\title{
Research on the Relationship between Piano Teaching in Colleges and the Cultivation of Students' Artistic Ability
}

\author{
Wei Zhang \\ Art College of XI'AN University, 710065
}

\begin{abstract}
Keywords: Piano Teaching; Cultivation of Students' Artistic Ability; Traditional Teaching; Education System Reform
\end{abstract}

\begin{abstract}
With the pursuit of higher quality spiritual life, music has become an indispensable part of our lives. Many colleges and universities have carried out reforms in the teaching system and opened a variety of art education courses. One of the key components is the music education that can cultivate students' innovative thinking ability. As a solo instrument of "the king of musical instruments", the teaching of piano has become an important subject of art education. In order to improve students' artistic ability training and independent learning and innovative thinking, it is necessary to improve the quality of piano teaching in colleges and universities. This paper mainly explores the relationship between college piano teaching and students' artistic ability training from the following three main aspects, the relationship between the cultivation of students' artistic ability in piano teaching in colleges and universities, the problems encountered in the current piano teaching process in colleges and universities, and the specific measures for the cultivation of students' artistic ability in college piano teaching.
\end{abstract}

\section{The Relationship between Piano Teaching in Colleges and the Cultivation of Students' Artistic Ability}

In order to strengthen the cultivation of comprehensive quality talents, the new curriculum reform focusing on the cultivation of students' comprehensive quality has become an inevitable trend of the transformation of the current teaching system with the development of the national education and teaching system reform. At the same time, it also puts forward a new requirement for the students' learning concept and the teacher's education concept. Especially in the classroom of piano education, teachers should integrate students' knowledge, skills and developmental intelligence of the piano, and pay more attention to the cultivation of students' artistic ability.

Cultivating students' artistic ability in piano education is the focus of the piano teaching process in colleges and universities. In addition to teaching piano professional skills, college piano teaching should also cultivate students' musical imagination and the ability of students to appreciate, express and create music. In addition to cultivating students' ability to comprehensively analyze problems, teachers should also improve students' creative imagination combined with practice. Therefore, piano is a compulsory course for college music majors.

The theoretical study and practice of piano teaching are inseparable, and its educational content and means should be consistent with students. Therefore, it is necessary to carry out targeted and purposeful teaching methods according to the objective laws of students' physiological and psychological development, and take appropriate ways and methods to carry out piano teaching activities, so as to achieve good results in the development of students' artistic ability.

\section{The Main Problems Encountered in the Current Piano Teaching Process in Colleges and Universities}

The piano teaching curriculum in colleges and universities not only can cultivate students' ability to develop piano foundations, but also can greatly enhance students' understanding of music art and cultivate students' innovative thinking ability because of its obvious flexibility and practical characteristics. Nowadays, in order to meet the needs of the society for piano music talents, the university adopts the "art ability training" as the core of new teaching concept, and the piano 
teaching has also adopted corresponding reform measures to continuously explore and develop. However, there are still many problems in the current college piano teaching shown as follows.

Some Teachers Are not High Quality and Students' Quality Is not Uniform. The basic piano skills of students often show mixed levels for various reasons. For example, a piano major with a solid piano basic skill, or a student with a little piano foundation, or a completely zero-based student, makes the student's grasp of the content unsatisfactory. In addition, the courses that students study are numerous and unfocused, and some college piano teachers have lower academic qualifications. Therefore, in the process of piano teaching, there are teaching disadvantages such as lack of pertinence, deep theoretical knowledge of piano and high-level piano skills. If teachers can't carry out specific analysis of specific problems in different levels and different piano foundations in teaching, it is difficult to solve the weak problems of various students' piano theory knowledge in a targeted manner.

Piano Education Teaching Methods Are Simplistic and One-sided. So far, in the traditional piano teaching, the teaching methods of teachers are relatively lacking in creativity and diversification. The purpose of teaching is more focused on the training and guidance of piano skills, but lacks the cultivation of piano appreciation and the construction of piano theory knowledge system, which is not conducive to the innovation of piano in the actual application process. This relatively simple teaching content and teaching method has few innovations in teaching forms and methods, which leads to the lack of systematic, normative and scientific evaluation of piano teaching. This traditional teaching concept and teaching mode are difficult to adapt to the huge number of piano professional students brought by the current college expansion. In addition, the problems in teaching feedback are manifested in the single way of evaluating students, and the lack of vitality in teaching classrooms can not promote students' learning autonomy. Therefore, it is difficult to carry out innovations and breakthroughs in college piano teaching methods, and it is more difficult to improve students' enthusiasm for learning and to cultivate students' artistic ability.

Colleges and Universities Do not Pay Enough Attention to Piano Teaching. Universities and teachers do not pay enough attention to the standard of piano teaching and the curriculum. The investment of capital, human resources and material resources in piano teaching are less and the location of the classroom often leads to the closure of the teaching environment and the disconnection between theory and practice. Most schools do not pay enough attention to piano teaching. Many teachers and students often think that the social demand of piano is not large, the employment rate is low, and the practicality is not strong. There is a negative view on piano teaching. Due to the fact that the actual piano classroom teaching less time, it is difficult to meet the learning needs of some students who want to improve their piano performance. Coupled with the lack of practice and investment in teachers, there is a certain degree of lag in the current piano teaching in colleges and universities.

To sum up, the blind expansion of colleges and universities leads to the quality of students is not good, which make traditional college piano teaching is difficult to achieve the best use. The lack of music teachers, the blind choice of teaching materials, the backward teaching methods, the lack of clear teaching plans and the corresponding reward and punishment system for teachers, and the lack of good teaching and training for students are the main drawbacks of traditional college piano teaching.

\section{The Specific Methods and Measures of Piano Teaching in Colleges and Universities to Cultivate Students' Artistic Ability}

In view of the main problems faced by the current piano teaching in the previous chapter, colleges and universities must take certain measures to optimize the teaching of piano education, improve the quality and effect of piano teaching and cultivate students' artistic ability.

Improving the Artistic Quality of Students and Cultivating Artistic Compound Talents Are the Main Training Objectives of Piano Teaching. Colleges and universities should actively optimize the piano enrollment system and clarify the entrance examination requirements to ensure 
the students' piano foundation. Strengthening students' ideological education requires students to have a broad understanding of the professional characteristics of music works and the development of piano teaching theories, so that students can fully understand the importance of piano lessons, rather than becoming a skill class for students to master a skill. In teaching practice, students can independently participate in the creation and analysis of piano music works, improve skills and culture. Colleges and universities should reasonably set up piano courses, highlighting the cultivation of artistic skills such as piano skills and theory as well as music appreciation skills. The teacher develops a teaching plan that is conducive to perfect teaching, carries out the whole teaching process and pays attention to the training and teaching of skills in this process, and combines the problems encountered in the actual practice of piano theory teaching to make timely changes.

Change Teaching Concepts, Enrich Teaching Forms and Innovate Teaching Modes. Change teachers' ideas and let them establish a sense of responsibility. In order to better realize the transformation from the traditional teaching mode to the modern piano teaching mode and guide students to improvise the arrangement and creation, it is necessary to establish a new teaching concept that has the characteristics of the times and is more in line with the characteristics of students' learning. At the same time, teachers must have a certain high-tech operation ability based on professional music literacy and piano performance. To change the teaching concept of schools and teachers, colleges and universities should strengthen the moral cultivation of piano teachers. Teachers should take the improvement of piano teaching quality as their responsibility and pursuit, fully recognize their diversified roles in the teaching process, and correctly understand the role of piano teaching in cultivating students' artistic ability. Strengthen the communication between teachers and students in the teaching process, and establish a new relationship between teachers and students. Teachers learn the professional ethics requirements and continuously improve the professional ethics. Besides, teachers should select appropriate piano teaching content and teaching methods according to students' needs and ability level. Students who have a large difference in piano performance should be treated differently, individual counseling for weak students, and use the collective advantage to activate the classroom atmosphere and optimize the teacher-student relationship. In addition, teachers also need to give students some opportunities to perform on important occasions, give students enough space for personalized development, and let students feel the atmosphere of live performance. Leave a lot of teaching time to students, let them show themselves, accumulate performance practical experience, and then improve their playing skills and artistic ability.

Colleges and Universities Should Strengthen the Construction of Humane Environment Atmosphere and the Allocation of Teaching Resources. Create teaching scenarios to cultivate students' artistic innovation thinking ability. In the piano teaching class, teachers let students contact the music works of different styles and understand the sentiments and form their own unique understanding of the specific music works. Besides, teachers should also encourage and help students to create themselves, stimulate students' imagination and creativity, and let students actively explore and innovate. Universities should increase their investment in hardware facilities such as pianos, so that each student has a piano to practice and improve their skills. Combining piano with life practice is the inevitable trend of piano education in colleges and universities in China.

Combine the Mode of Internet+ to Realize the Sharing of Teaching Resources and Strengthen the Construction of Teachers. Using the Internet as the medium to carry out network teaching to realize the interconnection of teaching resources. Piano teachers and students can share rich database resources and make full use of the advantages of multimedia technology to make various types of multimedia courseware. Students from non-music colleges can also pave the way for the theoretical knowledge of piano and the cultivation of practical skills through lectures by famous teachers. Teachers are encouraged to hold various forms of personal piano performances. Colleges and universities should stipulate that teachers should listen to each other, and employ experts and professors with high academic abilities and rich experience in classroom teaching as 
lecturers to regularly offer piano teaching lectures and open classes. The new and old teachers will study the piano teaching together, and regularly organize the piano teachers to participate in professional training to strengthen the professional training skills and improve the piano professional knowledge structure, thereby improving the teaching professional ability of the piano teachers. Expatriate learning to improve the professional level of piano teachers. Besides, strengthen the ideological and political work of piano teachers and conduct regular assessment and supervision to enhance the responsibility of piano teachers. Finally, piano teachers do a good job in the teaching process, pass on positive thoughts to students and let them become active in learning the piano.

Improve the Assessment System for Students' Piano Performance. Establish an evaluation system that combines the usual and final grades of students' subjective initiative, and attaches importance to the evaluation of students' encouragement. At the same time, it also attaches great importance to the developmental teaching evaluation that pays attention to the effectiveness of students' learning processes and methods.

\section{Conclusion}

Piano teaching plays an important role in cultivating the artistic ability of college students. The main problems presented in current piano teaching also confirm that there is still much room for development in this field of teaching. Therefore, colleges and universities should standardize piano teaching, supplement the faculty strength, and combine the theoretical knowledge and practice of piano teaching to cultivate students' basic skills. Besides, piano teachers should also pay attention to communicate with students when they teach, put students into the dominant position of teaching and create a good learning environment to mobilize the active participation of students. According to the different needs of different students, teachers will teach students in accordance with their aptitude and give full play to the subjective initiative of students. Therefore, piano teaching in colleges and universities should optimize teaching methods and face problems and obstacles in teaching. In the piano teaching, we must perfect the teaching mode, and constantly explore and innovate to make breakthroughs, so that students can comprehensively improve the quality of artistic ability in the experience and perception of music works. The ultimate goal of piano learning is to cultivate professional art talents with comprehensive quality, to help students improve their artistic ability, and to provide a solid foundation for students to better adapt to society in the future.

\section{Reference}

[1] H. Fu. New Requirements, New Thinking and New Measures-Discussion on the Reform of Piano Teaching in Teachers Colleges [J]. Journal of Chengdu Education College, 2004, (6).

[2] S. Zhang. Talking about the Measures and Methods of Improving Students' Music Literacy in Piano Education in Colleges and Universities [J]. China Science and Education Innovation Guide, 2012.

[3] Y. Yang. Talking about Music Innovation Education in Local Undergraduate Colleges Should Pay Attention to Instrumental Music Teaching [J]. Journal of Hunan Institute of Science and Technology, 2006 (12).

[4] P. Jing. Discussion on the Measures and Methods to Improve Students' Music Literacy in College Piano Education [J]. Music Time and Space, 2015, (11): 140-140.

[5] M. Liu. Application and Discussion of Multimedia Technology in Music Teaching in Higher Normal Colleges [J]. Chinese Medical Education Technology, 2008, (05).

[6] T. Tian. Reflections on How to Cultivate Students' Innovative Ability in Piano Teaching in Colleges and Universities [J]. Journal of Changsha Railway University (Social Science Edition), 2014, (4): 96-97.

[7] X. X. Zhang and J. K. Wang. Strategies for Improving Students' Music Literacy in Piano Education in Colleges and Universities [J]. Journal of Chifeng University(Natural Science), 2014. 
[8] H. Y. Wang. Strategies for Improving Students' Music Literacy in Piano Education in Colleges and Universities [J]. Reading and Writing (Education and Teaching Research), 2015, (16): 233-233. 